\title{
ARTIGO
}

do1 https://doi.org/10.22481/praxisedu.v16i41.6483

\section{UTILIZAÇÃO DAS TECNOLOGIAS DE INFORMAÇÃO E COMUNICAÇÃO NO ENSINO DA LÍNGUA INGLESA E SEUS DESAFIOS NA FORMAÇÃO DOCENTE}

\author{
USE OF INFORMATION AND COMMUNICATION TECHNOLOGIES IN THE \\ TEACHING OF ENGLISH LANGUAGE AND ITS CHALLENGES IN TEACHER
}

TRAINING

USO DE LAS TECNOLOGÍAS DE LA INFORMACIÓN Y LA COMUNICACIÓN EN LA ENSEÑANZA DEL IDIOMA INGLÉS Y SUS DESAFÍOS EN LA FORMACIÓN DOCENTE

Denilson Marques dos Santos Universidade do Estado do Pará - Brasil

Maria Cecilia Fagundes da Costa Universidade Anhanguera - Brasil

Denise Marques dos Santos Faculdade Pan Amazônica - Brasil

Resumo: O presente trabalho tem como objetivo identificar os benefícios e os desafios do ensino do inglês atrelado ao uso das Tecnologias de Informação e Comunicação (TIC's), além de analisar a formação de professores para o uso crítico dessas ferramentas em sala de aula. Para tanto, foi realizada uma breve revisão de literatura que traz à tona nomes como FRANCO (2018), IFA (2006), MOITA LOPES (2008), RODRIGUES (2016) e outros teóricos que agregaram em seus conhecimentos sobre a temática aqui abordada. Como resultado, demonstra-se que a metodologia tradicional de ensino do inglês suportada pelo quadro branco e a oralidade gera desinteresse, desmotivação e consequentemente dificulta o processo de aprendizagem do idioma. O estudo permite concluir que no período em curso, as tecnologias já fazem parte da realidade dentro e fora das escolas e por isso os professores são impelidos as constantes atualizações que apontam para o domínio de novas linguagens, ou seja, é preciso que eles também sejam letrados digitalmente. É essencial a instrução acerca do uso didático das TIC's a fim de oportunizar aulas de língua inglesa mais alinhada com a era digital.

Palavras Chave: Língua Inglesa. Formação de Professores. Tecnologias de Informação e Comunicação. 
Abstract: The present work aims to identify the benefits and challenges of teaching English tied to the use of Information and Communication Technologies (ICT's), in addition to analyzing the training of teachers for the critical use of these tools in the classroom. To this do so, a brief literature review was conducted that brings up names such as FRANCO (2018), IFA (2006), MOITA LOPES (2008), RODRIGUES (2016) and other theorists who added in their knowledge on the theme addressed here. As a result, it is demonstrated that the traditional methodology of teaching English supported by the whiteboard and orality generates disinterest, demotivation and consequently hinders the language learning process. The study allows us to conclude that in the current period, technologies are already part of reality inside and outside schools and so teachers are urged to constantly update the domain of new languages, that is, they must also be digitally literate. Instruction on the didactic use of ICT is essential in order to give opportunities for English language classes more aligned with the digital age.

Keywords: English Language. Training of Teachers. Information and Communication Technologies.

Resumen: El presente trabajo tiene como objetivo identificar los beneficios y retos de la enseñanza del inglés ligado al uso de las Tecnologías de la Información y la Comunicación (TIC), además de analizar la formación de los profesores para el uso crítico de estas herramientas en el aula. Para ello, se llevó a cabo una breve revisión bibliográfica que aportó nombres como FRANCO (2018), IFA (2006), MOITA LOPES (2008), RODRIGUES (2016) y otros teóricos que añadieron en sus conocimientos sobre el tema abordado aquí. Como resultado, se demuestra que la metodología tradicional de enseñanza del inglés apoyada por la pizarra y la oralidad genera desinterés, desmotivación y, en consecuencia, dificulta el proceso de aprendizaje de idiomas. El estudio nos permite concluir que en el período actual, las tecnologías ya forman parte de la realidad dentro y fuera de las escuelas, por lo que se insta a los profesores a actualizar constantemente el dominio de los nuevos idiomas, es decir, también deben ser alfabetizados digitalmente. La instrucción sobre el uso didáctico de las TIC es esencial para dar oportunidades a las clases de inglés más alineadas con la era digital.

Palabras Clave: Lengua Inglesa. Capacitación de los Maestros. Tecnologías de La información y la Comunicación.

Minha segurança se funda na conviçção de que sei algo e de que ignoro algo a que se junta a certeza de que posso saber melhor o que já sei e conhecer o que ainda não sei (FREIRE; SHOR, 1996: p. 153).

\section{Considerações iniciais}

A inserção das Tecnologias de Informação e Comunicação (TIC's) em sala de aula vem crescendo gradativamente e em virtude das potencialidades dos seus recursos elas se tornaram grandes aliadas no processo de ensino e aprendizagem das diferentes disciplinas, inclusive a língua inglesa. As $T I C$ ' $s^{1}$ quando bem empregadas podem facilitar o aprendizado do aluno além de potencializar a ação docente, pois elas contribuem para um amplo acesso às

\footnotetext{
${ }^{1} \mathrm{O}$ termo TIC designa o conjunto de recursos tecnológicos e computacionais para criação, utilização e armazenamento da informação. A sua principal característica é a agilização. Podemos utilizar e guardar grandes quantidades de conteúdos. Facilita e promove de forma rápida o acesso e a comunicação em redes. Possibilita a digitalização, o tratamento de texto, a edição de imagem, vídeo, som,... (TAJRA, 2001, p. 36).
} 
diversas fontes de informações, bem como proporcionam novos meios para a obtenção de conhecimentos sobre os diferentes contextos subjacentes à realidade.

Franco (2018, p. 195) nos afirma que: Apesar de trazer consigo um leque de possibilidades para a ampliação do ensino e proporcionar uma aprendizagem mais criativa a utilização das tecnologias ainda esbarra na rejeição por parte dos docentes quanto à sua aceitação e uma das prováveis causas para isso seja devido ao fato de que a formação inicial dos professores não contribuiu de forma efetiva para o uso crítico das TIC's em sala de aula. Destarte, esses profissionais não possuem conhecimentos sobre o manuseio de tais ferramentas, tampouco sabem como incorporar as atividades em língua inglesa aos recursos tecnológicos.

Diante do cenário delineado, o presente estudo tem como questão problematizadora o seguinte questionamento à correta utilização desses recursos em sala de aula. Para embasá-lo, optou-se por uma revisão de literatura, contando com o levantamento de material já produzido acerca da temática pesquisada: Quais são as possibilidades de intervenção do fazer pedagógico em língua inglesa utilizando as tecnologias da informação e comunicação?

Concomitante a esta indagação, propõe-se como objetivo central desta pesquisa identificar os benefícios e os desafios da introdução das TIC's no ensino do inglês regimentada pela Base Nacional Comum Curricular (BNCC), visto que ela aborda a questão discutida neste estudo e a importância da formação docente para a temática aqui apontada.

A relevância desta investigação se justifica pelo fato de que na sociedade hodierna, o inglês tem se tornado o idioma cada vez mais necessário e a introdução dos aparatos tecnológicos em sala de aula pode representar uma via de extrema importância para a evolução do ensino e aprendizagem da referida língua.

Além disso, este trabalho tem como finalidade contribuir com as práticas docentes ao apontar as proporções singulares que o ensino do inglês toma a partir da exposição as TIC's ao passo em que revela as lacunas da formação de professores para o uso crítico e significativo desses recursos.

\section{A globalização e o papel do inglês no século XXI}

Desde o final do século XX, a expressão "globalização"2 se popularizou de tal forma que passou a fazer parte do dia a dia em sociedade, ainda que muitos não soubessem defini-la

\footnotetext{
2 O discurso da "globalização" tem dois sentidos. Um descritivo ou simbólico, referido à suposta unificação do mundo. Outro, prescritivo ou normativo, representado pelas políticas neoliberais muito concretas, implementadas por agentes e instituições gestoras do capitalismo dominante (MOITA LOPES, 2008, p. 321).
} 
muito bem. De lá para cá, o que o senso comum captou de imediato foi tudo aquilo o que viria a cercar esse termo e que de certa forma se confirma no século XXI: Aumento das mobilidades, das trocas, das interações entre povos e culturas (RODRIGUES, 2016, p. 05).

Para Giddens (1990, p. 64): A globalização é a "intensificação das relações sociais mundiais que unem localidades distantes de tal modo que os acontecimentos locais são condicionados por eventos que acontecem a muitas milhas de distância e vice versa." Desta maneira, este estreitamento das interações entre povos e culturas garante à globalização força para interferir em todos os setores da sociedade e o seu impacto pode ter diferentes nuances a partir do nível de desenvolvimento das nações envolvidas no processo.

Rodrigues (2016, p. 17) infere que: "Se isso afeta de modo evidente todos os setores da sociedade e afeta também necessariamente aquele profissional cujo objeto de estudo e de trabalho está no cerne desse processo: O professor de língua estrangeira." Nesta direção temos a necessidade de se estabelecer uma linguagem eficiente de comunicação capaz de conectar as sociedades e consequentemente, aproximar as culturas fez com que o ensino de uma língua estrangeira se tornasse fundamental em todo o mundo sendo que o inglês é o idioma preferencial das publicações científicas, da internet, do comércio internacional e o mais utilizado por importantes organizações mundiais.

O papel do inglês no mundo contemporâneo é explicado pela importância que o Império Britânico teve no século XIX e no início do século XX pela predominância mundial da economia dos Estados Unidos a partir da Segunda Guerra Mundial, gerando um tipo de neocolonialismo ou imperialismo. (MOITA LOPES, 2008, p. 325).

No contexto presente, a língua inglesa não se restringe ao domínio do império (americano/britânico) sendo, portanto um patrimônio de todos. Neste sentido, Brumfit (2001) pontua que: $\mathrm{O}$ inglês não mais pertence numericamente aos 'falantes nativos' ${ }^{3}$ haja vista que a propriedade de adaptar e mudar qualquer língua estão no fato de como as pessoas a usam, independentes se elas sejam multilíngues ou monolíngues.

Se antes o inglês era um privilégio de poucos, hoje é uma necessidade de muitos. Pois, vivemos em um mundo cada vez mais globalizado, "tecnologizado" ou "digitalizado" (LANKSHEAR; KNOBEL, 2003, p. 137), grande parte da informação está disponível online e em inglês e por isso se faz cada vez mais necessário o domínio sobre este idioma, bem como o

\footnotetext{
${ }^{3}$ È todo aquele indivíduo no qual é exposto a uma língua em uma determinada comunidade ou região. A fala é adquirida naturalmente e o indivíduo pode ser considerado um falante competente da comunidade linguística da qual faz parte (BRUMFIT, 2001, p. 120).
} 
letramento digital a fim de adquirir autonomia para o uso e acesso das ferramentas tecnológicas que possibilite a inclusão digital e consequentemente favoreça o exercício de uma cidadania global.

Portanto, no mundo contemporâneo de complexidades e diversidades, principalmente do ponto de vista social e linguístico: O inglês se torna peça fundamental, já que se espalha pelo mundo através de processos socioeconômicos, políticos e culturais ligados ao fenômeno da globalização. (FADINI, 2016, p. 28).

O que se percebe na atualidade é que o inglês está sendo utilizado para a mudança social, uma vez ele que fornece aos usuários nativos ou não nativos da língua a possibilidade de integração ao mundo globalizado ao passo em que contribui para o aumento das perspectivas pessoais, profissionais e culturais.

Não há dúvidas de que o domínio do referido idioma aponte para o crescimento, desenvolvimento e acima de tudo melhores condições para acompanhar as rápidas transformações que ocorrem em escala mundial.

\section{As TIC's no ensino da língua inglesa}

Tecnologia é o termo genérico para designar todo o produto do conhecimento científico especializado. De forma mais abrangente engloba todo e qualquer método, objeto ou técnica, criado pelo ser humano, com o objetivo de tornar as atividades mais eficientes. Neste sentido, nem todas as tecnologias são de interesse educacional, mas há uma gama delas que podem contribuir significativamente com o processo educacional, dessa maneira, as tecnologias de informação e comunicação presentes na sociedade, cada vez mais conectada, possuem potencial para criar e alavancar uma aprendizagem significativa (TAROUCO, 2013, p. 28).

O advento das TIC's causou significativas alterações em diversos setores da sociedade, inclusive nas escolas e no processo de ensino e aprendizagem, os quais aparecem cada vez mais associados a esta nova realidade. Vale frisar que as TIC's contemplam não só o computador e a internet, mas também abarcam "um conjunto cada vez mais vasto de tecnologias de pequena escala: Portáteis, tablets, netbooks, mas também telemóveis, iPads, iPods e iPhones, além de dispositivos de reconhecimento e ativação por voz, TV móvel, etc" (RAMOS; TEODORO; FERREIRA, 2011, p. 15).

Assim sendo, é possível dizer que os espaços educacionais estão reconhecendo cada vez mais a introdução das TIC's em sala de aula como ferramentas que facilitam o processo de ensino e aprendizagem das diferentes disciplinas, bem como favorece a obtenção do conhecimento em uma língua estrangeira como é o caso da língua inglesa (MAGALHÃES; 
MACHADO; SILVA, 2015, p. 07). Saber usufruir dessas ferramentas para enriquecer a aula, utilizando-as para potencializar as práticas pedagógicas e assim contribuir para o desenvolvimento das competências e habilidades em um segundo idioma é o grande desafio dos professores de línguas estrangeiras do século XXI, os quais ainda utilizam o quadro branco e a oralidade como metodologias tradicionais.

Contudo, na Base Nacional Comum Curricular (BNCC) é previsto o uso das tecnologias pelos alunos e sua utilização deve ser feita de maneira crítica e responsável ao longo da Educação Básica, sendo ela tão importante que transforma-se em um dos pilares da BNCC colocada a mesma como cultura digital inserida no processo de ensino e aprendizagem atualmente.

Na BNCC (2017) existem duas competências gerais que estão relacionadas ao uso das tecnologias que são a quarta e a quinta respectivamente: $\mathrm{Na} 4^{\mathrm{a}}$ temos a sua utilização nos diferentes tipos de linguagens: Verbal (oral ou visual-motora, como Libras, e escrita), corporal, visual, sonora e digital, bem como conhecimentos das linguagens artísticas, matemática e científica, param se expressar e partilhar informações, experiências, ideias e sentimentos em diferentes contextos e produzir sentidos que levem ao entendimento mútuo e na $5^{\mathrm{a}}$ encontramos sua compreensão, utilização e criação (inovação) das tecnologias digitais de informação e comunicação de forma crítica, significativa, reflexiva e ética nas diversas práticas sociais (incluindo as escolares) para se comunicar, acessar e disseminar informações, produzir conhecimentos, resolver problemas e exercer protagonismo e autoria na vida pessoal e coletiva e porque não dizer até no aprendizado de uma língua estrangeira (no caso específico o inglês) pelos discentes.

Sobre isto, Franco (2018, p. 08) adverte que o vínculo entre o discente e a tecnologia é inegável, pois além de se intensificar a cada dia acaba divergindo da sua realidade escolar na qual muitas vezes a transmissão de saberes e conteúdos são realizados por meio de materiais clássicos como: Lousa, giz, caderno e caneta. Logo, é ingênuo pensar que em face da dinâmica do mundo atual, a forma tradicional de ensino atenda às necessidades e expectativas educacionais dos alunos (os quais são verdadeiros nativos digitais na atualidade) haja vista que esta metodologia provoca um absoluto desinteresse por parte de muitos estudantes e consequentemente dificulta o aprendizado.

O discente está cada vez mais digital e inserido em uma cultura interativa e participativa, a qual pede novas maneiras de ensinar e novas formas de aprender. No entanto, o modelo de ensino que se oferta é tradicional e 
analógico, não suportando as necessidades desse aluno digital (ALBUQUERQUE, 2015, p. 42).

Desta forma, fica nítido que "não há mais espaço para estratégias pedagógicas e metodológicas de caráter conteudista, que equalizam aprendizagem e memorização" (FINARDI; PREBIANCA; MOMM, 2013, p. 175). Logo, educar essa nova geração de alunos demanda a reciclagem das práticas pedagógicas herdadas do século passado posto que o corpo discente da atualidade tem acesso rápido e fácil a diversas fontes de informação e em virtude disso, os educadores precisam encontrar formas significativas de incorporar à língua inglesa atividades mediadas pelas TIC's.

Paiva (2013) afirma que: A importância do uso das tecnologias é ressaltada diariamente na imprensa, nos artigos e livros acadêmicos e corporativos. Assim sendo, não há como negar a presença das TIC's na educação, pois elas já fazem parte da realidade dentro e fora das salas de aula. Destarte, a promoção do ensino do inglês em um contexto caracterizado pelas tecnologias pode contribuir para o desenvolvimento linguístico dos alunos por meio da inserção em situações reais de uso do idioma.

Partindo da percepção desta realidade é possível inferir que o processo de ensino e aprendizagem de línguas e aqui em especial a língua inglesa, ganha outras dimensões, tendo em vista o contato consideravelmente amplo do aluno ao idioma fora da sala de aula (BALADELI; FERREIRA, 2012, p. 18). Tal afirmação se ratifica ao observar que cada vez mais o estudante utiliza a televisão, o computador, o celular, a internet, e outras mídias como parte integrante do seu cotidiano e como consequência apropriar-se dos novos conteúdos além daqueles transmitidos pelo docente.

Embora, as TIC's sejam compostas por diversos meios técnicos que possibilitam um melhor aproveitamento e expansão do tempo e espaço da escola. Porém, foi a internet o recurso tecnológico que mais alcançou destaque nos ambientes educacionais graças ao seu aspecto dinâmico e de fácil manuseio. Tal recurso permitiu ao aluno usar a língua-alvo ${ }^{4}$ para se integrar em comunidades autênticas de usuários e trocar experiências com pessoas do mundo todo que estudassem a língua utilizada (LEFFA, 2006, p. 71).

A Internet traz muitos benefícios para a educação, tanto para os professores
como para os alunos. Com ela é possível facilitar as pesquisas, sejam grupais
ou individuais, e o intercâmbio entre os professores e alunos, permitindo a
troca de experiências entre eles. Podemos mais rapidamente tirar as nossas
duvidas e dos nossos alunos, sugerir muitas fontes de pesquisas. Com todas

${ }^{4} \mathrm{Em}$ aprendizagem é a língua estrangeira que alguém pretende aprender (busca dominar) (BALADELI; FERREIRA, 2012, p.87). 
estas vantagens será mais dinâmica a preparação de aula" (TAJRA 2001. p. 148).

Finardi e Porcino (2014, p. 259) entendem que: A internet não somente reafirma o status do inglês como língua internacional, mas como também, modifica os paradigmas de ensino do referido idioma. Na medida em que o usuário é introduzido no ambiente virtual da internet, ele tem a oportunidade de conhecer e desenvolver as competências comunicativas na língua alvo por meio de um maior contato com o idioma, haja vista que o inglês é o dialeto mais recorrente no ciberespaço além de ser o veículo preferencial das relações comerciais, das descobertas científicas e dos avanços tecnológicos.

\begin{abstract}
Portanto, no mundo internetizado de hoje que declarou o inglês como língua internacional e transmite informação através de cliques, quem não domina o idioma e não é digitalmente letrado está excluído de várias formas de mediação de conhecimento através da linguagem - seja ela a linguagem tecnológica ou o inglês como língua internacional. (FINARD; PREBIANCA; MOMM, 2013, p. 197).
\end{abstract}

Para Costa et al. (2007, p. 99): “As inúmeras possibilidades de interação, acesso, comunicação, memória e intermediação que a Internet proporciona, fazem dela um importante ambiente pedagógico para pesquisas, tanto por parte dos professores quanto dos alunos". Nesta direção, depreende-se que a embora a internet traga consigo um leque de possibilidades para a melhoria da educação, ela também pode atrapalhar e/ou desviar a atenção dos alunos, pois tamanha é a quantidade e a diversidade das informações que ela disponibiliza.

A este respeito, Tajra (2001) pontua que apesar dos inúmeros benefícios a internet também apresenta algumas desvantagens, tais como: o excesso de informações sem fidedignidade, facilidade na dispersão durante a navegação e facilidade do acesso a sites inadequados para o público discente. Neste caso, a escola desponta como o local ideal para discutir as possíveis soluções dos problemas relacionados ao uso impróprio da internet e dos demais recursos tecnológicos, bem como a reflexão sobre os conhecimentos indispensáveis à adequada aplicação dessas ferramentas no ambiente educacional.

Diante destas colocações depreende-se que na atualidade a introdução das TIC's na educação aponta para uma área promissora, mas também, cercada de desafios e questionamentos. Destarte, é imprescindível que não somente os professores de língua inglesa, mas no geral que todos saibam fazer o uso crítico das tecnologias nas práticas pedagógicas, e também, sejam capazes de escolher "as melhores soluções para cada situação de aprendizagem, que facilitem a comunicação com os alunos, que orientem a confecção dos materiais adequados 
para cada curso que humanizem as tecnologias e as mostrem como meios e não como fins" (MORAN, 2012, p. 48).

\section{Formação do professor de língua inglesa para o uso crítico das tecnologias}

A formação de professores de inglês tem sido foco de análise por vários estudos e pesquisas na última década e o que justifica tamanho interesse por essa temática está relacionado, primeiramente, ao fato da expansão e relevância que a língua inglesa alcançou no mundo todo (MAGALHÃES; MACHADO; SILVA, 2015, p. 19). Considerando, pois, este processo de compreensão da formação docente, vários estudos são desenvolvidos com o propósito de investigar e sugerir novos caminhos para a promoção do crescimento profissional e aperfeiçoamento das práticas pedagógicas dos professores de inglês e, consequentemente, a elevação da qualidade do ensino desse idioma.

Todavia, para compreender o estado da formação do professor de língua inglesa na era digital e/ou tecnológica, torna-se relevante, primeiramente entender o mundo em que vivemos. No período em curso, presenciamos uma época marcada pela intensificação da globalização, “cujo resultado marcante é o pensamento único que impõe uma visão exclusiva fazendo com que a produção e a difusão de conhecimentos, bem como o ensino e a pesquisa sigam parâmetros já estabelecidos” (IFA, 2006, p. 26-27).

Em meio a esse cenário, é possível destacar que a explosão tecnológica e informacional, impulsionada, principalmente, pelo uso da internet, contribuiu de forma significativa para o surgimento de uma sociedade conectada em rede aonde as pessoas, as informações e os conhecimentos são constantemente compartilhados de forma democrática (FERREIRA, 2016). Tal fenômeno impactou não somente os aspectos sociais, políticos, econômicos e culturais, mas também, se refletiu na esfera educacional.

Sobre este contexto, Costa et al. (2007, p. 94) ressaltam que os espaços educativos "tiveram que reformular muitos de seus conceitos e práticas pedagógicas, a fim de tornar a escola, de fato, em um espaço/tempo competitivo e de excelência num mundo cambiado pelas inovações tecnológicas". Neste sentindo, o cenário delineado aponta para uma inovação na área educacional, contudo, é indispensável realizar primeiramente uma reflexão sobre o preparo e o conhecimento dos professores, aqui em especial os de língua inglesa para o uso crítico destas ferramentas em sala de aula.

Ao longo da sua formação, os professores de inglês têm sido desafiados a lidar com a complexidade de ensinar um segundo idioma em diferentes contextos nos quais são inseridos. 
Um dos grandes desafios impostos no cotidiano desses profissionais está relacionado ao fato de que hoje em dia, exige-se deles "mais que um grupo de habilidades cognitivas, especialmente, se ainda for levada em consideração a lógica presente no universo digital e nas mídias" (FRANCO, 2018, p. 196).

A formação de docentes para o uso das TIC's no processo de ensino/aprendizagem é uma questão recente na América Latina e ocorre com o amadurecimento dos processos de modernização tecnológica das escolas. Grande parte dos formadores de docentes na região sequer está no grupo dos chamados "imigrantes digitais", isto é, não tiveram a oportunidade de se habilitar à adoção das novas tecnologias anos após sua própria formação docente e no exercício profissional em escolas desprovidas dessa tecnologia. Muitos continuam, de fato, à margem das inovações. Grande parte, talvez a maioria dos docentes em exercício nas escolas primárias e secundárias não aprendeu os rudimentos do uso das novas tecnologias e muito menos suas aplicações educacionais durante a formação. (ROBREDO, 2003, p. 37).

Em outras palavras, o advento da tecnologia impele os professores para o domínio de novas linguagens, ou melhor é preciso que eles também sejam letrados digitalmente falando. Tal processo demanda competências de abrangências distintas e em virtude disso, torna-se necessário incluir nos currículos dos cursos de Licenciatura o preparo docente para "A fluência tecnológica que permite conectar a educação libertadora com as demandas do mundo do trabalho" (ALMEIDA, 2005, p. 157).

\begin{abstract}
A inclusão e o uso de uma nova tecnologia não podem ser implantados sem reflexão e treinamento adequado. O professor precisa participar de programas de capacitação antes de aplicar o novo método em sala de aula. Com as TIC's, vem junto as transformações, no modo de pensar pedagógico, nova maneira de ensinar, nova forma de lidar com o saber e principalmente como gerenciar as informações. O grande desafio é preparar as pessoas para lidar com essas novas formas de viver, pensar, ensinar e aprender. Entende-se que essas pessoas sejam capazes de reconstruir o modo de ensinar e aprender (ANDRADE, 2014, p. 45).
\end{abstract}

Neste sentido, Magalhães, Machado e Silva (2015, p. 35) alertam que: Apesar dos avanços tecnológicos e das inúmeras possibilidades que as TIC's têm proporcionado ao processo de ensino e aprendizagem, o uso que os docentes fazem dessas ferramentas ainda é parco. Por esse motivo, compete a formação de professores clarificarem a dimensão do papel social que o docente possui além de fornecer espaço para o reconhecimento das potencialidades e desafios que o uso pedagógico dessas tecnologias acarreta.

Se de um lado verificamos a falta de capacitação adequada para o uso das TIC's, por outro, percebemos que alguns professores ainda resistem ao uso desses equipamentos. Logo, a 
formação de professores deve acompanhar as "inovações tecnológicas ", ${ }^{5}$ entretanto, deve-se perceber que a questão determinante não é a tecnologia, mas a forma como ela é empregada. Sharma e Barret (2007) lembram que as TIC's devem ser usadas tanto para aprimorar os planos de aula quanto para torná-las interativas e motivadoras para professores e alunos, mas em nenhuma hipótese devem substituir a função docente.

O professor de inglês da atualidade deve atentar para o fato de que "a mudança do olhar discente sobre o aprendizado da língua inglesa não é impossível, porém sua ocorrência está intimamente ligada à forma com a qual este aprendizado é abordado pelo docente" (FRANCO, 2018, p. 8). A autora ainda pontua que usar técnicas inovadoras para o ensino é uma exigência atual, pois além de despertar o interesse para o 'aprendizado crítico ${ }^{66} \mathrm{e}$ significativo de uma segunda língua, também colabora para a conexão dos conteúdos aprendidos em sala à realidade que ultrapassa os muros da escola.

Isso posto, a formação de professores é um processo eminentemente contínuo, logo, a busca por melhores competências e qualificações profissionais deve ser uma atitude igualmente contínua. Os professores de inglês devem estar cientes do contexto atual e das demandas dele provenientes, para que seja possível realizar um trabalho dinâmico, inovador, e que utilize toda a tecnologia disponível para a o ensino eficaz e significativo da língua em questão.

\section{Considerações finais}

Esta revisão bibliográfica averiguou o impacto e as potencialidades do uso das tecnologias de informação e comunicação no âmbito da aprendizagem da língua inglesa por meio de uma análise minuciosa dos estudos que abordam o tema em questão. Além disso, procurou investigar e refletir sobre os desafios contemporâneos que a formação de professores de inglês enfrenta.

De acordo com a discursão ao longo do texto, foi possível perceber primeiramente que a sociedade hodierna tem passado por diversas transformações com destaque especial para a inserção das tecnologias em diversas esferas, inclusive nos espaços educacionais. Em virtude disto, as metodologias de ensino sofreram impactos significativos apontando para a necessidade de refletirmos e atualizarmos nossas abordagens e os materiais utilizados em sala de aula, para

\footnotetext{
${ }^{5}$ É um termo aplicável as inovações de processos e de produtos. Sendo muito importantes, pois ajudam o desenvolvimento e diminuem os custos de produção nas empresas (SHARMA; BARRETT, 2007, p. 84).

${ }^{6} \mathrm{Na}$ perspectiva do aprendizado crítico, professores e alunos percebem-se como agentes transformadores e passam a se considerar atuantes no processo de transformação sociocultural e concebem a importância da coragem e da vontade de mudar suas realidades, a fim de proporcionar meios para uma (re)significação da escola (FREIRE; SHOR, 1996: p. 73).
} 
que assim, a escola consiga acompanhar as mudanças advindas da globalização advindas até com as tecnologias digitais.

Fica evidente que nos dias atuais não se pode negar o convívio das TIC's em diversas áreas, inclusive na educação. Por isso, faz-se necessário que os cursos de formação de professores revisitem os seus currículos a fim de preparar os docentes para o reconhecimento das potencialidades e obstáculos que essas ferramentas podem trazer tanto para o ensino quanto para a potencialização da ação pedagógica. Vale salientar que a utilização dos recursos tecnológicos não se restringe somente ao contexto das disciplinas de língua estrangeira, em especial o inglês, mas também, podem ser implantados em qualquer área do conhecimento, desde que haja um correto preparo e atenção para o uso crítico delas.

É essencial que a formação do estudante de Letras/Inglês contribua para a instrução dos futuros docentes sobre o uso didático das TIC's, já que, segundo as pesquisas mencionadas ao longo do texto, essa é uma realidade atual e que já faz parte da rotina de muitos alunos. Logo, os professores de inglês precisam buscar alternativas para adaptar o ensino do idioma ao contexto tecnológico, no intuito de atender às expectativas e necessidades educacionais dessa nova geração de nativos digitais.

A presente pesquisa também ressaltou o computador e a internet como algumas das principais ferramentas tecnológicas que pode contribuir significativamente para a promoção do letramento digital e o acesso à informação através do domínio do inglês como língua estrangeira. Espera-se que esse trabalho tenha despertado o desejo de refletir sobre a formação de professores para a integração destas duas linguagens: A do inglês e a da tecnologia, visto que ambas fazem parte dos novos letramentos e demandas do mundo contemporâneo.

Por fim, este trabalho não intenta inserir as TIC's no ambiente escolar a qualquer custo, mas sim, evidenciar os benefícios que estas ferramentas proporcionam ao serem incluídas de forma consciente no Brasil pela BNCC no processo de ensino e aprendizagem também da língua inglesa, bem como ressaltar que por si sós elas não podem ser encaradas como um fim, mas sim, como complementos essenciais à construção do conhecimento e fortalecimento da ação docente.

\section{REFERÊNCIAS}

ALBUQUERQUE, O. C. P. O uso das ferramentas da web 2.0 no processo ensinoaprendizagem da língua inglesa: Um estudo na escola de idiomas Yázigi na cidade de São Luís. 2015. 182 f. Dissertação (Mestrado) - Universidade Federal do Maranhão, Programa de Pós-Graduação em Cultura e Sociedade, 2015. 
ALMEIDA, M. E. B. Letramento digital e hipertexto: Contribuições à educação. In PELLANDA, N. M. C.; SCHLÜNZEN, E. T. M.; SCHLÜNZEN JUNIOR, K. (Org.). Inclusão digital: Tecendo redes afetivas/cognitivas. Rio de Janeiro: DP\&A, 2005.

ANDRADE, M. Ensino de língua inglesa e as novas tecnologias: Mediações pedagógicas e interação social. Monografia (Aperfeiçoamento/Especialização em Práticas Pedagógicas Interdisciplinares) - Universidade Estadual da Paraíba. 2014.

BALADELI, A. P. D.; FERREIRA, A. J. Os letramentos digitais e sua interface com o ensino de línguas: Empoderamento e cidadania na Web. In: Congresso anual da ABRAPUI, 3, 2012, Florianópolis. Anais do III Congresso Internacional da ABRAPUI. Florianópolis, 2012.

BRASIL. Base Nacional Comum Curricular (BNCC). Educação é a Base. Brasília, MEC/CONSED/UNDIME, 2017. Disponível em:

$\langle$ http://basenacionalcomum.mec.gov.br/images/BNCC_publicacao.pdf $>$. Acesso em: 12 mar. 2020.

BRUMFIT, Christopher. Teaching english as a world language. In: Individual Freedom in Language teaching: Helping learners to develop a dialect of their own. Oxford, OUP, 2001, p. $115-125$.

COSTA, W. A. et al. Recursos informacionais: Importante aliado no processo de elaboração dos planos de aulas. Encontros Bibli: Revista eletrônica de biblioteconomia e ciência da informação, Florianópolis, v. 12, n. 23, p. 92-112, nov. 2007.

FADINI, K. A. Formação inicial de professores de inglês do e para o século XXI: Os papéis da língua e da tecnologia. 2016. 350 f. Dissertação (Mestrado em Linguística) - Centro de Ciências Humanas e Naturais, Universidade Federal do Espírito Santo, Vitória, 2016.

FERREIRA, J. K. S. A formação do professor de língua inglesa para o uso das Tecnologias da Informação e Comunicação em sala de aula. In: III CONEDU, 2016, Natal. Anais III CONEDU. Campina Grande: Editora Realize, 2016. v. 1.

FINARDI, K. R.; PORCINO, M. C. Tecnologia e metodologia no ensino de inglês:

Impactos da globalização e da internacionalização. Ilha do Desterro, Florianópolis, v. 1, n. 66, p. 239-283, 2014.

FINARDI, K.; PREBIANCA, G.; MOMM, C. Tecnologia na Educação: O caso da internet e do inglês como linguagens de inclusão. Revista Cadernos do IL, v. 46, p. 193-208, 2013.

Disponível em: http://seer.ufrgs.br/cadernosdoil/article/view/35931/25846 Acesso em: 17 fev. 2020.

FRANCO, Bárbara Alves da R. O uso das TIC's como instrumento para ensino da língua inglesa: Perspectivas e desafios. Revista CBTecLE, v. 1, p. 193-202, 2018.

FREIRE, Paulo; SHOR, Ira. Medo e Ousadia: O cotidiano do professor. 10 ed. Rio de Janeiro: Paz e Terra. 1996. 
GIDDENS, Anthony. Sociology. Oxford: Polity Press. 1990.

GONZALEZ, Mariade las Nieves L. O uso de aplicativos educativos de alfabetização para celulares: Os novos desafios da educação moderna. Revista acadêmica RPGM, São Paulo, v. 1, n. 2, p. 283-290, jul./out. 2017. Disponível em:

http://fics.edu.br/index.php/rpgm/article/view/591 Acesso em: 12 mar. 2020.

IFA, Sérgio. A formação pré-serviço de professores de língua inglesa em uma sociedade em processo de digitalização. Tese (Doutorado em Linguística Aplicada) - Pontifícia Universidade Católica, São Paulo, 2006.

LANKSHEAR, C; KNOBEL, M. New Literacies: Changing knowledge and classroom learning. Buckingham: Open University Press, 2003.

LEFFA, V. J. Nem tudo que balança cai: Objetos de aprendizagem no ensino de línguas. Polifonia. Cuiabá, v. 12, n. 2, p. 15-45, 2006.

MAGAlHÃES, J. R. S. ; MACHADO, L. ; SILVA, T. A. Formação de professores de inglês para o uso das TIC's: Reflexões sobre teoria e prática. In: $8^{\circ}$ encontro de formação de professores, 2015, Aracaju - SE. Anais do $8^{\circ}$ ENFOPE, 2015.

MOITA LOPES, L. P. Inglês e globalização em uma epistemologia de fronteira: Ideologia linguística para tempos híbridos. DELTA, São Paulo, v. 24, n. 2, p. 309-340, 2008.

MORAN, J. M. A educação que desejamos: Novos desafios e como chegar lá. 5. ed. São Paulo: Papirus, 2012.

PAIVA, V. L. M . O. A formação do professor para uso da tecnologia. In: SILVA, K.. A.; DANIEL, F. G.; KANEKO-MARQUES, S. M.; SALOMÃO, A. C. B. (Orgs) A formação de professores de línguas: Novos Olhares - Volume 2. Campinas, SP: Pontes Editores, 2013. pg. 209-230.

RAMOS, J. L.; TEODORO, V.; FERREIRA, F. Recursos educativos digitais: Reflexões sobre a prática. Cadernos SACAUSEF VII. 2011. Disponível em:

http://dspace.uevora.pt/rdpc/bitstream/10174/5051/1/1330429397_Sacausef7_11_35_RED_re flexoes_pratica.pdf Acesso em: 08 mar. 2020.

ROBREDO, Jaime. Da ciência da informação revisitada aos sistemas humanos de informação. Brasília, DF: Thesaurus: SSRR Informações, 2003. 245 p.

RODRIGUES, L. C. B. A formação do professor de língua estrangeira no século XXI:

Entre as antigas pressões e os novos desafios. Signum: Estudos da Linguagem, Londrina, v. 2, n. 19, p. 13-34, dez. 2016.

SANTOMÉ, Jurjo Torres. A Educação em tempos de neoliberalismo. Porto Alegre: Artes Médicas, 2003.

SANTOS, Denilson M. dos; COSTA, Maria Cecilia F. da; MORAES, Erika Meireles de; BRITO, Ana de Fátima; SILVA, Alan Ceber C. da. 2018. Uma análise da garantia dos 
direitos de crianças e adolescentes no município de Belém-PA. Revista Multidisciplinar Pey Këyo Científico / ISSN 2525-8508, América do Norte/USA, Vol. 4, nº 1, 1-22 p.

SHARMA, Pete; BARRETT, Barney. Blended learning: Using technology in and beyond the language classroom. Oxford: Macmillan, 2007.

TAJRA, S. F. Informática na educação: Novas ferramentas pedagógicas para o professor na atualidade. 3.ed. São Paulo: Érica, 2001.

TARGINO, Maria das Graças. Comunicação científica: Uma revisão dos seus elementos básicos. Informação e Sociedade: Estudos, João Pessoa, v. 10, n. 2, 2000. Disponível em: http://www.ies.ufpb.br/ojs2/index.php/ies/article/view/326/248 Acesso em: 03 fev. 2020.

TAROUCO, Liane Margarida Rockenbach. Um panorama da fluência digital na sociedade da informação. In: BEHAR, Patricia Alejandra (Org.) Competências em educação a distância. Porto Alegre: Penso, 2013.

\section{SOBRE OS AUTORES:}

\section{Denilson Marques dos Santos}

Mestrado (em curso / 2020-2022), Universidade do Estado do Pará / UEPA; MBA em Gestão Educacional e Docência do Ensino Básico e Superior (concluída), Instituto Carreira; Pedagogo, Universidade Estácio de Sá (UNESA); Secretaria Executiva de Educação (SEDUC-PA) Brasil; Programa de Pós-Graduação em Filosofia; Grupo de Pesquisa FILOSOFIA PRÁTICA (Política, Ética e Direito) / UFPA/IFCH-FAFil. E-mail: dede_cecilia@yahoo.com.br

(iD http://orcid.org/0000-0003-0359-4695

\section{Maria Cecilia Fagundes da Costa}

Especialização em Políticas e Direitos da Criança, Adolescente e Juventude (em curso / 20202021), Grupo Educacional YADAIM OVDOT - Brasil; Programa de Pós-Graduação em Serviço Social; Grupo de Pesquisa Políticas Públicas e Direitos Humanos. E-mail: cecilia8775@yahoo.com.br

(iD http://orcid.org/0000-0001-5706-1806

\section{Denise Marques dos Santos}

MBA em Gestão e Recursos Humanos (concluída), Instituto Carreira; Direito (em curso / 2020 2025) Faculdade Cosmopolita - Brasil; Programa de Pós-Graduação em Educação; Grupo de Pesquisa FILOSOFIA PRÁTICA (Política, Ética e Direito) / UFPA/IFCH-FAFil (ouvinte). Email: dede_lana@hotmail.com

iD http://orcid.org/0000-0002-3313-5783

Recebido em 09 de abril de 2020

Aprovado em 07 de agosto de 2020

Publicado em: 07 de setembro de 2020 